\title{
Desapropriando o currículo: Imagem, prática educativa e experiência vivida no movimento anarcopunk
}

\author{
Dispossessing the curriculum: Image, educational practice and experience lived \\ in the anarcho-punk movement
}

Maurício Remígio

\begin{abstract}
Resumo
Este texto apresenta aspectos de caminhos metodológicos percorridos numa pesquisa que busca compreender como experiências vividas fora da escola podem se imbricar na escola através da prática educativa. Discute, também, a relação aprendizagem/conhecimento como prática local que pressupõe considerar ações e significados do cotidiano. Práticas educativas inspiradas em experiências vividas no movimento anarcopunk - organizar-se coletivamente sem hierarquias - são utilizadas como estratégia de ensino. A coleta de dados foi realizada através de grupo focal, com cinco meninos e cinco meninas em uma escola pública municipal da cidade de Macapá Amapá.
\end{abstract}

Palavras chave: pesquisa qualitativa, experiência vivida, prática educativa, anarcopunk.

\section{Abstract}

This text presents aspects of a methodological pathway followed in a research that aims to understand how experiences lived outside school can mingle into school through educational practice. It also discusses the learning/knowledge relation as a local practice which presupposes to consider daily life actions and meanings. Educational practices inspired in lived experiences in the anarcho-punk movement - collective organization without hierarchies - are used as teaching strategy. Data was collected through focal groups organized with five boys and five girls from a city public school in Macapá, State of Amapá.

Keywords: qualitative research, lived experience, educational practice, anarcho-punk movement.

A motivação para a realização deste estudo surge a partir do momento em que, como professor de artes, passei a observar a presença persistente de narrativas hegemônicas no currículo e, em decorrência, a rigidez e a expectativa das instituições de ensino no sentido de que essas narrativas sejam implementadas pela ação do professor. Essa ação muitas vezes coloca o professor na posição de guardião do currículo.

A aspereza e as contradições do currículo, aliadas às exigências constantes das instituições escolares no sentido de preservá-lo, tem gerado incômodos e impulsionado embates que, aos poucos, podem sinalizar a possibilidade de negociação em meio a essas relações de poder. Esses embates surgem do entendimento de que "o currículo não é um elemento inocente e neutro de transmissão desinteressada de conhecimento social" (MOREIRA e SILVA, 2005, p. 8), e, consequentemente, torna inevitável que a escola passe a ser vista como um "território de luta" (GIROUX e SIMON, 2005). 
Minha curiosidade e interesse pelo tema se intensificaram à medida que fui me dando conta de que a escola não é mais o único ou, talvez, o lugar privilegiado para construção de conhecimento. Hoje, estamos enredados por complexas e múltiplas dimensões de nossas vidas das quais (...) "fazem parte os diferentes conhecimentos, práticas, experiências, percepções, inserções que nos constituem" (OLIVEIRA e SGARBI, 2008, p. 74).

Esta compreensão me motiva a entrelaçar significados de mundo construídos fora da escola, prática escolar e atuação docente. No momento em que busco dar sentido às minhas ações em sala de aula, memórias e perguntas referentes à minha trajetória fora da escola se tornam constantes. Tais perguntas tem gerado questionamentos relacionados às experiências vividas durante minha participação no movimento anarcopunk $^{1}$. Começo me perguntando: que relações posso fazer entre prática educativa em arte e significados de mundo constituídos durante minhas vivências no movimento anarcopunk?

De acordo com Tourinho (2008), é "no jogo entre memória e invenção que organizamos, reconstruímos e qualificamos nossas experiências" (p. 73). Nesse sentido, também encontro apoio nas reflexões de Goodson (2000), quando alerta que a "origem sociocultural é um ingrediente importante na dinâmica da prática profissional" (p. 72). Ainda referindo-se às pesquisas sobre vida de professores, Goodson destaca a importância do "estilo de vida do professor dentro e fora da escola, as suas identidades e culturas ocultas [como aspectos que] têm impacto sobre os modelos de ensino e sobre a prática educativa" (p. 72).

Essas considerações tensionam a busca pela construção de espaços significativos nas práticas educativas e incitam possibilidades de construir e favorecer a produção de sentidos na vida profissional com os sujeitos envolvidos nos processos de aprendizagens. Essas reflexões norteiam e impulsionam meu desejo de investigar entrecruzamentos entre significados de mundo constituídos fora da escola e a prática educativa que desenvolvo como professor.

Assim, me pergunto: como experiências vividas por professores e alunos, fora e dentro da escola, podem se imbricar na prática escolar? Que sentido têm tais vivências para o

\footnotetext{
${ }^{1}$ Home (2004), localiza o surgimento do anarcopunk na Inglaterra, no fim da década de 70, através do "Crass". Banda formada por Hippies com intuito de disseminar a propaganda anarquista, e que politizou de forma veemente o faça-você -mesmo. Traz no seu histórico ações de trotes e shows em imóveis abandonados e por eles ocupados.
} 
cotidiano escolar? Como se localiza e intersecciona a prática educativa através dos estudos da cultura visual?

\section{O Movimento Anarcopunk: cotidianizando a política}

Como participante ativo do movimento punk fui desafiado a aprender a desconstruir, ou, colocando à maneira punk, fui instado a destruir vínculos com qualquer pretensão de autoritarismo. Lembro muito bem da letra da banda potiguar, "Discarga Violenta" que, através do hardcore ${ }^{2}$, em questão de segundos e em meio a um visceral ruído, se ouviam os gritos: "toda autoridade é um abuso". O título da música era, "Abuso de autoridade".

Ainda nesse período da adolescência, fui provocado a desconfiar do mundo via estranhamento e comecei a desafiá-lo pelo viés da estética punk ${ }^{3}$. Permitia-me discordar de tudo o que me foi ensinado em instituições, incluindo família, escola e igreja. 0 hardcore, os eventos de protesto em praça pública, as gigs ${ }^{4}$ e os fanzines ${ }^{5}$ se apresentaram como espaço sedutor a ser construído e ocupado pelo sentimento de indignação provocado pelo repúdio às desigualdades sociais, aos preconceitos e à miséria que, embora visíveis e deploráveis, nunca foram abordados ou problematizados nas instituições escolares por onde passei. O movimento punk infiltrou-se no Brasil no fim dos anos 70, mas o movimento anarcopunk ganhou força somente no final dos anos 80 . Enredados pela aspiração e desejo de debater questões sociais, os jovens do movimento anarcopunk se organizam em grupos não hierarquizados para realizar eventos, desenvolver estudos, mas, sobretudo, para fazer protestos (SOUSA, 2002). Para os anarcopunks, visual e música não ficam em segundo plano, mas, a importância maior passa a ser o envolvimento na luta contra injustiças sociais. Daí a necessidade de "criar um espaço mais teórico para refletir sobre a realidade social e ao mesmo tempo, divulgar e popularizar as ideias anarquistas dentro de suas comunidades" (SOUSA, 2002, p.107).

\footnotetext{
${ }^{2}$ No fim dos anos 80 ao escapar da apropriação do punk rock pela indústria cultural e do assédio da cultura de consumo o punk reaparece no mundo. Dessa vez através do 'hardcore' que significa algo visceral, intenso, agressivo. Essa agressividade não está presente apenas na música, mas, no próprio visual (vestimenta) e no teor político, orientado pelo protesto e pela resistência aos padrões sociais.

${ }^{3}$ Estética punk entendida como o visual, o hardcore ou anti-música, o faça você mesmo e a androgenia que, articulados pelo punk, se apresentam como uma agressão aos padrões sociais buscando sabotar o consumo e o lucro, instigando a autonomia e desvios constantes de enquadramentos.

4 Tipo de show sem estrelas

${ }^{5}$ O termo fanzine surgiu em meados dos anos 70 na Inglaterra resultado do cruzamento das palavras "fan" e " Magazine". O primeiro fanzine foi produzido por um bancário chamado Mark Perry.
} 
Em relação às práticas desenvolvidas pelos anarcopunks, Oliveira (2008) situa a formação dos integrantes desses grupos na esfera das pedagogias libertárias ${ }^{6}$ e, principalmente, no âmbito da pedagogia libertadora de Paulo Freire. Imbuídos deste ideal, os jovens engajados no movimento anarcopunk começaram a criar ambientes educativos coletivos, não hierarquizados, informais, cujo objetivo era discutir questões do cotidiano a partir de um enfoque anarquista.

Nesse contexto, ideias libertárias são aliadas à pedagogia libertadora privilegiando, mas, sobretudo, valorizando as interpretações de mundo dos jovens punk, abrindo caminho para uma crítica ácida aos 'autores oficiais' e às 'grandes narrativas', ridicularizando a educação bancária (OLIVEIRA, 2008) e buscando refletir sobre suas convicções sociais e suas identidades cambiantes, opositoras.

O informativo "o punk \& a contracultura", editado por Renato Aiam (s/d), apresenta algumas premissas que orientam a cultura anarcopunk:

(...) são assumidos com veemência alguns princípios que fortalecem a cultura punk e a expõem com uma tônica totalmente libertária e libertadora. Questões como o anti-autoritarismo, ateísmo ativo, anti-sexismo/machismo, androginia/anti-homofobia, iconoclastia, irreverência, anti-capitalismo, autonomia/faça você mesmo, anti-racismo, etc... (...) As apresentações [das bandas] têm sempre a participação direta do público e nem sequer utilizam a palavra "show", mas sim "gigs" que é uma apresentação mais intimista (...) [porque] para os anarcopunks não existe separação entre banda e público (p. 4 -5).

O’Hara (2005), descreve a importância da ética punk como força que mobiliza, que impele ao exercício do movimentar-se, do não esperar, impulsionando os indivíduos a buscar/criar suas próprias estratégias de enfrentamento com o mundo com o intuito de potencializar e liberar coletivamente pequenas liberdades, mesmo que provisórias. Essa ética atribui significado e valor ao uso do Faça - você - mesmo (FVM), ou, do it yourself (DYI), uma "extensão dos princípios anarquistas que requerem responsabilidade e cooperação para construir um [presente e quem sabe um] futuro mais produtivo, criativo e agradável" (p. 162). Através do FVM e posicionados a partir dessas brechas e espaços, os punks lutam para realizar suas produções sem intermediários, sem esperar por outros, experimentando e construindo experiências a seu modo. Dessa maneira, eles vivenciam e estimulam uma prática transgressora como ação política.

\footnotetext{
${ }^{6}$ A respeito das pedagogias libertárias ver: Pedagogia libertária: anarquistas, anarquismos e educação. Silvio Gallo. São Paulo. Imaginário. Editora da Universidade Federal do Amazonas. 2007
} 
Nesse momento da minha vida, cheguei a abandonar dois cursos universitários. Não havia espaço para concessões, numa sociedade perversa que torna legal a magnificência de alguns em detrimento da crueldade e da miséria de tantos outros. Só me restava à recusa, a rebeldia, sentimento de indignação que tentávamos manifestar publicamente através de panfletos, ações coletivas, sabotagens. Sentimento que, de alguma forma ainda trago comigo, hoje como professor de arte.

\section{Politizando o cotidiano}

Do ponto de vista da educação, entender aprendizagem e conhecimento como pratica local pressupõe não perder de vista ações e significados do cotidiano. Segundo Oliveira e Sgarbi (2008), isso pressupõe tornar visíveis conhecimentos muitas vezes ofuscados pelo pensamento hegemônico de estudos estruturais, generalizantes, que, com frequência, mantêm-se afastados das questões que inscrevem as noções de cotidiano. Por esta razão, o conhecimento produzido nas práticas cotidianas pode passar despercebido, turvado pela impossibilidade de ser abordado em sua complexidade. Assim, é necessário entender o conhecimento cotidiano em suas especificidades, evitando reduzi-lo a "uma instância do real dissociada das estruturas nos quais se inscreve, mas como o campo no qual essas últimas se efetivam, sempre de acordo com as possibilidades e circunstâncias específicas de cada espaçotempo". (OLIVEIRA e SGARBI, 2008, p. 69)

Concordando com Oliveira e Sgarbi (2008), compreendemos o conhecimento como um "processo em rede", como sentidos tramados coletivamente pela interação entre sujeitos, sentidos que vão além da ideia dominante de conhecimento como algo preexistente, fragmentado e hierarquizado, pronto para ser alcançado de forma linear e individual. Para os autores, a compreensão de conhecimento como um processo tecido coletivamente, em redes de sujeitos, cria possibilidades para se "questionar a base de legitimação da dominação contemporânea: a superioridade do saber científico sobre as demais formas de conhecimento do mundo e a consequente superioridade daqueles que os detêm sobre os demais sujeitos" (p. 80). Em termos da prática docente, incorporar esta perspectiva implica

(...) revalorizar os saberes cotidianos e outros modos de conhecer o mundo, reconhecendo em todos eles incompletudes e potencialidades, significa promover a horizontalização das relações entre os diversos saberes, e essa democratização pode ser uma importante contribuição para a criação de novos conhecimentos. (OLIVEIRA e SGARBI, 2008, p. 80-81) 
Assim, ação pedagógica e pesquisa devem ser pensadas como uma articulação de espaços onde diferentes vozes possam ser ouvidas "no sentido de relacionar a pesquisa qualitativa às esperanças, às necessidades, aos objetivos e às promessas de uma sociedade democrática livre" (DENZIN e LINCOLN, 2006, p. 17).

\section{Cotidiano e pesquisa}

Para relacionar a pesquisa às promessas, necessidades e esperanças de indivíduos em uma sociedade/escola democrática livre, é importante visualizar as fronteiras entre pesquisador e pesquisado, ou, entre professores e alunos, como referências provisórias, móveis, flexíveis, sempre dependentes do contexto e das circunstâncias em que se realiza a investigação, principalmente quando o foco da pesquisa está orientado para a construção de diálogos entre conhecimento cotidiano e prática docente. Faz-se necessário pensar e planejar as ações de forma ativa, mas não hierarquizada, de modo que pesquisador e colaboradores possam dialogar num clima de confiança e reciprocidade.

Denzin e Lincoln (2006), ao discutir as implicações dessas questões na pesquisa qualitativa - cotidiano, fronteiras, contexto - explicam que,

Os pesquisadores qualitativos ressaltam a natureza socialmente construída da realidade, a íntima relação entre o pesquisador e o que é estudado, e as limitações situacionais que influenciam na investigação. Esses pesquisadores enfatizam a natureza repleta de valores da investigação (p. 23).

Nesse sentido, a investigação qualitativa constitui-se, principalmente, como um conjunto de práticas que buscam estabelecer diálogos entre os sujeitos envolvidos numa "tentativa de assegurar uma compreensão em profundidade do fenômeno em questão" (DENZIN e LINCOLN, 2006, p.19). Apresenta-se, também, como um campo orientado à interpretação e como uma atividade que "localiza o observador no mundo" (DENZIN e LINCOLN, 2006, p.17).

Desse modo, a coleta de dados pode ser compreendida como uma prática que busca captar na dinâmica dos cenários naturais uma visibilidade do mundo social e, a partir dessa dinâmica e apoiada nessa visibilidade, descreve "momentos e significados rotineiros e problemáticos da vida dos indivíduos" (DENZIN e LINCOLN, 2006, p.17). Como cenário natural, entendemos os lugares onde as experiências do cotidiano se desenvolvem, espaços onde as relações e dinâmicas do cotidiano ganham sentido, 
significado e valor. Denzin e Lincoln (2006) caracterizam e descrevem com clareza esses cenários detalhando que...

(...) a pesquisa qualitativa envolve uma abordagem naturalista, interpretativa, para o mundo, o que significa que seus pesquisadores estudam as coisas em seus cenários naturais, tentando entender, ou interpretar, os fenômenos em termos dos significados que as pessoas a eles conferem. (p.17)

Fundamentados nesses princípios organizamos a coleta de dados através de grupos focais realizados com alunos da Escola Municipal de Ensino Fundamental Roraima, na cidade de Macapá - AP. A partir de convites e mediante a autorização dos pais/responsáveis, participaram como colaboradores desse estudo dez estudantes da sétima série do turno da manhã, cinco meninos e cinco meninas, na faixa etária de 12 a 14 anos.

\section{Construindo espaços de interação}

Termos como "entrevistas de grupo", "entrevista de grupo focal", ou, ainda, "discussão de grupo focal" são usados por distintos autores (BARBOUR, 2009) ao se referirem à coleta de dados com grupos. Por vezes, esses termos geram dúvida ou até mesmo confusão no que diz respeito à construção de um entendimento do que seja um grupo focal. Nesse sentido, Barbour destaca que a interação do grupo e o estímulo por parte do moderador nos diálogos e "conversa[s] entre si", é o que, de fato, caracteriza um grupo focal. A autora considera a definição proposta por Barbour (2009) apropriada para ajudar a compreender, mesmo que de maneira geral, o conceito de grupo focal: "Qualquer discussão de grupo pode ser chamada de um grupo focal, contanto que o pesquisador esteja ativamente atento e encorajando às interações em grupo" (p. 20).

Ao realizar a coleta de dados através de grupo focal com alunos da E.M.E.F. Roraima, pensamos numa forma de entrelaçar minhas experiências vividas em "bando", principalmente no movimento anarcopunk, com um procedimento metodológico que busca criar e construir uma situação coletiva. Essa estratégia metodológica tem por objetivo dialogar com e ouvir, em um contexto específico, os vários e diferentes posicionamentos dos sujeitos mantendo em perspectiva o fato de que na vivência grupal "a partilha e o contraste de experiências constrói um quadro de interesses e preocupações comuns que, em parte experienciadas por todos, são raramente articuladas por um único indivíduo" (GASKELL, 2002, p.77). 
Com o intuito de orientar o foco para as perguntas que inquietam e, consequentemente, nos levaram a realização desta pesquisa, construímos e utilizamos um "guia de tópicos (roteiro)" (BARBOUR, 2009). O roteiro, uma espécie de guia flexível, não impediu o surgimento de questões adicionais, ou mesmo a reformulação dos tópicos inicialmente propostos, uma vez que durante as falas dos participantes, aconteceram discussões, debates, intervenções e complementos no sentido de adicionar ou reformular questões, ou, ainda, para suscitar o surgimento de outros tópicos e questões.

Com a intenção de estimular interações e discussões no grupo focal, solicitamos, também, que cada colaborador escolhesse uma imagem de revistas que disponibilizamos para o encontro. Orientados para escolherem a imagem que mais the chamasse atenção, em seguida propusemos questões a respeito da escolha das imagens para serem respondidas individualmente. Os colaboradores tiveram tempo para falar sobre a escolha das imagens, suas motivações, justificativas e preferências. Posteriormente, solicitamos que eles, através de recortes, alterações, superposições e colagens, acrescentassem outras imagens aquela escolhida inicialmente. Tomando como referência as associações/acréscimos feitos às imagens, pedimos que cada colaborador criasse uma narrativa e em seguida falasse sobre ela. As narrativas, além de estimular uma interação visual/imagética entre os colaboradores, também se apresentam como dados valiosos a serem analisados, uma vez que a interpretação de imagens "mobiliza a memória visual e reúne sentidos de memória social construída pelos indivíduos"(...) (MARTINS, 2010, p. 22)

\section{Um projeto via satélite}

Iniciava uma aula com uma turma de sexta série composta, em sua maioria, por alunos fora da faixa etária. Esses alunos eram marcados na escola como uma turma problema. Subitamente, um aluno me interrompeu para fazer uma pergunta. Queria saber "o que é uma transmissão via satélite". A pergunta do aluno desencadeou uma série de piadas e, especialmente, risos por parte da turma. Para os alunos, a pergunta não tinha nenhuma relação com o assunto que tratávamos naquele momento. Eu havia perguntado sobre o motivo da ausência de muitos colegas. Sem demora, eles responderam que os demais não estavam na escola porque preferiram "soltar pipa na rua". Encerrados os risos e piadas, decidi transferir a pergunta do aluno para a turma: o que é uma transmissão via satélite?

A conversa se prolongou com vários exemplos. Os alunos identificaram programas de computadores que possibilitam a visualização de imagens via satélite por meio da 
internet, a transmissão de partidas da copa do mundo, etc. No final da aula propus que pensassem e anotassem nos cadernos, o que diriam se pudessem ser ouvidos, pelo mundo, numa transmissão via satélite.

As mensagens anotadas pelos alunos abrangiam uma ampla gama de temas: arrependimentos de brigas familiares, alerta contra o uso de drogas, a importância de preservar a floresta amazônica, reclamações sobre a precariedade do laboratório de informática da escola, recados amorosos para namorados(as), questões religiosas, o prazer de soltar pipas, o perigo do uso de cerol nas pipas e assim por diante. Antes de sair da sala de aula fui provocado pelos alunos: "professor, o senhor podia dar uma aula pra gente soltar pipas"!

No encontro seguinte, apresentei para os alunos o trabalho de Cildo Meireles "Inserções em circuitos ideológicos: Projeto Coca-Cola, $1970^{\prime \prime 7}$, e a intervenção realizada pelo grupo Urucum, "Mensagens Vazias". ${ }^{8}$ A discussão, a partir da análise dos trabalhos, possibilitou a ampliação da concepção dos alunos sobre a produção de arte. Despertou à atenção dos alunos o fato dos trabalhos artísticos terem sido realizados com objetos como garrafas e a proposta do grupo urucum envolvendo pessoas que passavam na rua. Alguns alunos mostraram-se curiosos em relação às mensagens veiculadas nos trabalhos: "será que elas foram lidas por alguém?" Outros questionaram a ação do grupo Urucum ao jogar garrafões de vidro no rio.

A partir das observações da turma em relação ao trabalho de Cildo Meireles e do grupo Urucum, perguntei que relações podiam ser feitas entre as mensagens escritas nos cadernos, o desejo de soltar pipas na aula de arte e os trabalhos discutidos. Poucos alunos se manifestaram. Entre esses poucos, veio a proposta de um aluno: "a gente podia escrever mensagens nas pipas e depois empinar!"

Ao perguntar se a turma concordava com proposta do colega a sala virou uma euforia só. Nascia, ali, o que passei a chamar de "projeto via satélite". O projeto desencadeou uma

\footnotetext{
7 Cildo Meireles gravou em garrafas de refrigerantes retornáveis, informações e opiniões críticas, que eram devolvidas à circulação. Utilizou no processo decalques com textos em tinta branca vitrificada que não aparecem quando a garrafa esta vazia, ficando visível apenas com a presença do líquido escuro da coca-cola.

${ }^{8} \mathrm{O}$ grupo Urucum é um coletivo de artistas residentes em Macapá que realizou uma intervenção no réveillon de 2003 chamada "Mensagens Vazias". O grupo realizou a intervenção próximo a fortaleza de Macapá onde abordavam as pessoas pedindo que escrevessem seus desejos em bilhetes, e, em seguida, colocassem em garrafões que, posteriormente, seriam lançados no rio amazonas e, aos poucos, levados pela maré. Disponível em:

http://www.youtube.com/watch?feature=player_embedded\&v=IPN9BKqLizs \#!
} 
série de discussões/atividades chegando a uma intervenção urbana realizada na comunidade.

Outra questão que gerou polêmica durante as discussões foi a proposta de uma menina dizendo que "rabiola é coisa pra homem, não para mulher", e, por esse motivo, ela não participaria da ação. Em seguida a aluna recebeu apoio de uma colega ao confirmar que "pipa para mulher é muito feio". Outras alunas discordaram relatando que empinavam pipas e, portanto, não viam problemas nessa prática, pois não a consideravam coisa de homem. Esses posicionamentos encaminharam a aula para reflexões relacionadas a gênero, tendo como exemplo, os papeis definidos para homens e mulheres em diferentes sociedades e culturas.

Sugeri, então, que as mensagens, ao invés de escritas diretamente nas pipas, fossem escritas em recortes de papel. Além disso, propus que a atividade não ficasse limitada a turma, mas, que coletássemos mensagens em todas as turmas do turno da tarde incluindo funcionários, técnicos e professores. A proposta foi aceita na íntegra pelos alunos. Criamos uma comissão para coletar mensagens a partir da seguinte pergunta: Se você estivesse falando para o mundo, via satélite, que mensagem você enviaria para as pessoas que estariam lhe escutando?

Outras comissões foram formadas. Uma para colocar rabo nas pipas, e outra, para cortálas com tesouras. Intencionalmente, levei quarenta e oito pipas prontas, faltando apenas o rabo. Então, fui questionado pela turma: por que, para os alunos, "as pipas deveriam ser feitas na aula de arte, não é aula de arte professor, então?" Aproveitei os questionamentos para trabalhar com os alunos os conceitos de dadaísmo ${ }^{9}$ e ready mades $^{10}$. O grupo que escolheu cortar as pipas com as tesouras foi composto pelos alunos(as) que se recusaram a empiná-las.

As mensagens foram coletadas em todo o turno da tarde e coladas nas pipas. Os rabos foram confeccionados e colocados e, finalmente, as pipas estavam prontas para serem empinadas.

Em um dia de sol forte e calor, o vento estava propício para empinar pipas. Deslocamosnos até um campo de futebol utilizado pela comunidade levando quase trezentas

\footnotetext{
9 Movimento artístico surgido na Europa, no início do século XX, que tinha como objetivos contestar/romper com as concepções históricas de arte institucionalizadas e aceitas socialmente.

10 Tática utilizada por Marcel Duchamp, no fazer artístico, ao utilizar objetos do cotidiano prontos/industrializados na sua produção.
} 
mensagens coladas nas quarenta e oito pipas. Ficamos por lá até que a última pipa fosse empinada e cortada. A ação foi registrada em vídeo.

\section{Cultura visual, ensino de arte e experiência vivida}

Para Duncum (2011), por meio do diálogo e do debate aberto entre professores e alunos ou, o que ele chama de "pedagogia dialógica", pode-se chegar "a uma crítica que permite uma reflexão divertida e até mesmo transgressora", onde, alunos e professores aprendam. O autor explica que:

O objetivo de uma pedagogia dialógica que amalgama diversão e crítica não consiste em fornecer respostas definitivas, mas sim em levantar questionamentos, revelar dilemas e dar continuidade a uma conversa. Tal pedagogia crê no poder dos alunos e em sua capacidade de tomar decisões éticas (p. 26).

No que se refere a minha atuação como professor e as ações que tenho desenvolvido em sala de aula, tento considerar/problematizar as práticas cotidianas e as experiências estéticas vivenciadas pelos alunos. Essas ações norteadas pelas vivências cotidianas dos alunos muitas vezes contrastam com as exigências curriculares oficiais. São ações pedagógicas que dialogam com as práticas que os alunos estabelecem no seu dia-a-dia dentro ou fora da escola - com artefatos visuais diversos. Provocar reflexões, estranhamentos, dúvidas e questionamentos são parte da prática que acredito mover a ação educativa do professor na contemporaneidade, principalmente no que diz respeito ao ensino de arte e à diversidade de experiências que constituem as subjetividades dos alunos.

Nessa perspectiva, Aguirre (2009), ao reconhecer que os materiais curriculares não atendem aos repertórios estéticos juvenis e que estes se configuram como experiências estéticas vindas do entorno dos meios de comunicação e dos instrumentos eletrônicos, alerta para a necessidade de

Colocar no espectro de nosso âmbito de estudo a cultura popular e inclusive a cultura de massa; submeter esse tipo de prática à análise crítica e à desconstrução de suas relações com as tramas das hegemonias e do poder são ações que respondem, perfeitamente, aos fundamentos de uma educação artística renovada (p.169-170).

Dias (2006), referindo-se a educação da cultura visual, esclarece que propostas educativas orientadas por essa abordagem consideram as "experiências diárias do visual" numa perspectiva inclusiva de modo que as "diferentes formas de produção da cultura visual possam ser estudadas e entendidas de um modo mais relacional e contextual e 
menos hierárquicas" (p. 104). Esse posicionamento revela a dimensão política da educação da cultura visual que numa perspectiva inclusiva e aberta à diversidade de conhecimentos instiga "os sujeitos à consciência crítica e a crítica social como um diálogo preliminar que conduz à compreensão, e, então, à ação" (DIAS, 2006, p.104).

É visível a dicotomia entre escola e vida quando conteúdos curriculares entram por uma porta e alunos e professores entram e/ou saem por várias outras, como por exemplo, o desinteresse e a ausência de motivação dos alunos para freqüentar ou estar na escola. Ao observar essa dicotomia, penso que práticas pedagógicas entrelaçando subjetividade, cotidiano e coletivo podem abrir portas que conduzam à "polissemia" (SILVA, 2006, p. 9) ajudando a construção de sentidos no ambiente escolar de modo que possamos buscar "ressonâncias entre sensações, sentidos, ideais, sentimentos, ações" (TOURINHO, 2009, p. 142). Esta é uma tentativa no sentido de evitar dicotomias e encurtar distâncias entre conhecimento e contexto, professores e alunos, escola e vida.

Ao observar que a educação não se restringe apenas a instituições escolares e situa-se num âmbito mais abrangente numa "variedade de áreas sociais", Steinberg e Kincheloe (2004) denominam "pedagogia cultural" os locais onde "o poder é organizado e difundido", sejam eles a televisão, cinema, brinquedos, revistas, etc.

Levando em consideração o modo de vida dos jovens na atualidade, a presença das "pedagogias culturais" em seu cotidiano e a ausência desses repertórios juvenis nos currículos, se faz necessário pensar ações educativas em arte que problematizem esses olhares orientados para essas pedagogias criando outras experiências de ver, sentir e pensar.

Tourinho e Martins (2011), ao constatarem que as instituições de ensino têm trabalhado a educação visual de maneira a instituir e homogeneizar os modos de ver dos alunos estabelecendo visões normativas sobre arte e imagem, propõem uma "compreensão crítica da cultura visual". Destacam a importância de desenvolver experiências educativas nas quais o "estranhamento visual" possa operar como um meio de desnaturalizar modos de ver institucionalizados e ordenados. Nessa perspectiva, os autores veem possibilidades de construir um "(...) olhar diferenciado que foge ao conforto e a estabilidade das rotinas visuais (...)" (p.61), ou seja, o que consideram um "olhar crítico". Esse olhar crítico nos "ajuda/orienta a desenvolver uma visão crítica do mundo e da realidade" (p. 61). 


\section{Referências}

AGUIRRE, Imanol. Imaginando um futuro para a educação artística. In: MARTINS, Raimundo e TOURINHO, Irene (Orgs.). Educação da cultura visual: Narrativas de ensino e pesquisa. Santa Maria: Editora da UFSM, 2009, p. 157-186.

AIAM, Renato (Org.). Informativo: o punk \& a contracultura. Sem data.

BARBOUR, Rosaline. Grupos focais. Tradução de Marcelo Figueiredo Duarte. Porto Alegre: Artmed, 2009.

DENZIN, Norman e LINCOLN, Yvonna S (Eds.). Introdução: a disciplina e a prática da pesquisa qualitativa. In: DENZIN, Norman e LINCOLN, Yvonna. O planejamento da pesquisa qualitativa: teorias e abordagens. Tradução de Sandra Regina Netz. Porto Alegre: Artmed, 2006, p. 15-41.

DIAS, Belidson. Acoitamentos: os locais da sexualidade e gênero na arte/educação contemporânea. In: MARTINS, Raimundo (Org.), Visualidades: Revista do Programa de Mestrado em Cultura Visual, V 4, 2006, n. 1 e 2, p.101-131.

DUNCUM, Paul. Por que a arte-educação precisa mudar e o que podemos fazer. In TOURINHO, Irene e MARTINS, Raimundo (Orgs.). Educação da cultura visual: conceitos e contextos. Santa Maria: Ed. da UFSM, 2011, p. 15-30.

GASKELL, George. Entrevistas individuais e grupais. In: BAUER, Martin W. e Gaskell (Eds.). Pesquisa qualitativa com texto, imagens e som: um manual prático. Tradução de Pedrinho A. Guareshi. Petrópolis: Vozes, 2002, p. 64-89.

GIROUX, Henry A. e SIMON, Roger. Cultura Popular e Pedagogia Crítica: a vida cotidiana como base para o conhecimento curricular. In: MOREIRA, Antonio Flávio Barbosa e SILVA, Tomaz Tadeu (Orgs.). Currículo, cultura e sociedade. Tradução de Maria Aparecida Baptista, 8a . Ed. São Paulo: Cortez, 2005, p. 93-124.

GOODSON, Ivor F. Goodson. Dar voz ao professor: as histórias de vida dos professores e o seu desenvolvimento profissional. In: NÓVOA, Antonio (Org.). Vidas de professores. $2^{\mathrm{a}}$ ed. Porto: Porto Editora, 2000. p. 63-78.

MARTINS, Raimundo. Pensando com imagens para compreender criticamente a experiência visual. In: RODRIGUES, Edvânia Braz Teixeira e ASSIS, Henrique Lima 
(Orgs.). Educação das artes visuais na perspectiva da cultura visual: conceituações, problematizações e experiências. Goiânia: SEDUC, 2010, p. 19-38.

MOREIRA, Antonio Flávio Barbosa e SILVA, Tomaz Tadeu. Sociologia e teoria crítica do currículo: uma introdução. In: MOREIRA, Antonio Flávio Barbosa e SILVA, Tomaz Tadeu (Orgs.). Currículo, cultura e sociedade. São Paulo: Cortez, 2005, p.7-37.

O'HARA, Craig. A filosofia do punk: muito mais do que barulho. Tradução de Paulo Gonçalves. São Paulo: Radical Livros, 2005.

OLIVEIRA, Inês Barbosa e SGARBI, Paulo. Estudos do cotidiano \& Educação. Belo Horizonte: Autêntica editora, 2008.

OLIVEIRA, Vantiê C. Carvalho de. O movimento anarco-punk: a identidade e a autonomia nas produções e nas vivências de uma tribo urbana juvenil. Natal: Editor Vantiê Clínio Carvalho de Oliveira, 2008.

SILVA, Tomaz Tadeu da. O currículo como fetiche: a poética e a política do texto curricular. $1^{\text {a }}$ ed. Belo Horizonte. Autêntica. 2006.

SOUSA, Rafael Lopes de. Punk: cultura e protesto - as mutações ideológicas de uma comunidade juvenil. São Paulo: Edições Pulsar, 2002.

STEINBERG, Shirley R. e KINCHELOE, Joe L. Sem segredos: cultura infantil, saturação de informação e infância pós-moderna. In: STEINBERG, Shirley R. e KINCHELOE, Joe L. Cultura infantil: a construção corporativa da infância. Tradução de George Eduardo Japiassú Bricio. 2a Ed. Rio de Janeiro: Civilização Brasileira, 2004.

TOURINHO, Irene. Ouvindo escolhas de alunos: nas aulas de artes eu quero aprender... In: MARTINS, Raimundo (Org.). Visualidade e Educação. Goiânia: FUNAPE, 2008.

Educação estética, imagens e discursos: cruzamentos nos caminhos da prática escolar. In: MARTINS, Raimundo; TOURINHO, Irene (Orgs.). Educação da cultura visual: narrativas de ensino e pesquisa. Santa Maria: Editora da UFSM, 2009, p. 141-156. 
TOURINHO, Irene e MARTINS, Raimundo. Circunstâncias e ingerências da cultura visual. In: MARTINS, Raimundo e TOURINHO, Irene (Orgs.). Educação da cultura visual: conceitos e contextos. Santa Maria: Ed. da UFSM, 2011, p. 51-68.

' Professor efetivo da Universidade Federal do Amapá. mauricio.remigio08@gmail.com

Recebido em: 23/09/2013

Aprovado em: 15/10/2013 